得ることが認められる。

\section{6. 結 論}

ガラスエポキシ基板上の銅ランドに銅合金 (C7250) リ ードを接合したマイクロソルダリング接合部に存在する 内部欠陥や，外部欠陥の検出の可能性の検討を, 熱伝導 シミュレーションと実験を用いて行い，以下の主な結論 を得た。

1）熱伝導モデルを構成し，レーザ照射時での接合部 の温度シミュレーションにより実験結果との捠差 $5 \%$ 以 下で接合部表面の温度分布を求める事が可能である。

2）接合状態を接合界面での熱伝達率汇よって表現し て接合部表面温度分布をシミュレーションにより解析し た結果, 接合界面の状態がリード表面の温度上昇に反映 されている.

3）接合界面に存在するボイドや末接合などの内部欠 陥を接合界面に熱流を遮断する領域を作成する事により 表現し，レーザ照射時での接合部温度をシミュレーショ ンにより解析した。その結果, 欠陷の存在している接合 部の表面温度 $\mathrm{T}_{(\mathrm{d}) \max }$ と, 欠陌が存在しない接合部の温度 分布の最高温度 $\mathrm{T}_{(\mathrm{n}) \max }$ の差 $\Delta \mathrm{T}_{\max }\left(\mathrm{T}_{(\mathrm{d}) \max }-\mathrm{T}_{(\mathrm{n}) \max }\right) に$ より欠楩情報が得られる事を示した。

4) ソルダー，2 種の接着㓮による接合部にレーザを 照射し，その表面温度を計湘する事により，接合材の違
いが表面温度情報により得られる事を実験的に示した。 この事は逆に表面温度情報より接合界面情報が得られる 事を物語っている。

5） 実際のQFP のガルウィング型リードのソルダリ ング接合部を対象として，接合部にレーザを照射し，接 合部熱画像を解析する事によりポイド，未接合など接合 欠陥の検出可能性があることを実験的に示した。

\section{参 考 文 献}

1）住日本プリント回路工業会編，“表面実莣技術(SMT) の動向調 查報告毒”，(神日本プリント回路工業会， (1992)，p. 319-351.

2）伸田ら：“低温反応接合材利用による接合プロセスの低温化お よび接合品質の向上”, 一微料電子材料の接合現象とプロセス制 御阔する研究(第 3 報)一, 溶接学会論文集, Vol. 11, No. 1, (1993), p. 202-208.

3）日本機械学会編, “伝熱工学資料 改訂第 4 版”, 日本機械学会, (1987), p. 314-316.

4）三菱電機粎，合金製品技術資料，No. 277006 .

5）日本マイクロエレクトロニクス協会編, “厚膜 IC 化技術”, 工業 調查会, (1984), p. 8.

6）岩田ら：「熱伝溥シミュレーションによる接合部の欠扸の検出 条件及び㭘出限界寸法の検副ーレーササ照射型熱画像法によるマ イクロ接合部欠陥検出に関する研究(第 2 報)一」, 溶接学会論文 集, Vol. 11 (1993), No.4, p. 515-519.

\title{
熱伝導シミュレーションによる接合部の欠陷検出条件 及び検出限界寸法の検討*
}

ーレーザ照射型熱画像法によるマイクロ接合部欠陥検出に関する研究（第 2 報）一

岩田 剛治**, 仲田 周次***

\begin{abstract}
Optimal Detection Condition and Minimum Defect Size for Detection
\end{abstract}
by Computer Simulation*

--Detection Process on the Defect in the Micro Joints by Infrared

Thermal Imaging with Laser Irradiation (2nd report) -

$$
\text { by Yoshiharu Iwata** and Shuji Nakata*** }
$$

The position and size of internal defect, optimal detection condition and minimum defect size on the inspection are investigated on the computer simulation on thermal model of the joint.

The size and position of internal defect can be determined by the area of temperature above $T_{c}$ on the joint surface, and then optimal detection condition (laser power, taking time of thermal image) are decided by the relation between temperature behavior of the joint under laser irradiation and characteristics of thermography.

Furthermore, minimum defect size on the inspection is influenced by kinds, thickness of the lead and thermal transfer coefficient at the interface of the joint, and is nearly $50 \mu \mathrm{m}$ in the case of the micro joint between cepper alloy lead with $150 \mu \mathrm{m}$ thickness and glass epoxy substrates (1.6 mm thickness).

Key Words : detection process, micro-joints, interface, thermal imaging, heat transfer coefficient, laser, computer simulation

\footnotetext{
*原稿受付 平成 5 年 5 月28日 平成 4 年度秋季全国大会で発表

**学生員大阪大学大学院 Student Member, Graduate School, Osaka Univ.

***正員 大阪大学工学部 Member, Faculty of Eng., Osaka Univ.
} 


\section{1. はじめに}

本研究は,レーザ照射型熱画像法によりマイクロ接合 部の欠陷検出方法に関するもので, 前報では, ガラスエ ポキシ基板上の銅ランド上にリードを接合したマイクロ ソルダリング接合部, ヒータチップ接合によりアルミナ 基板上の $\mathrm{Ag} / \mathrm{Pd}$ ランド上にリードを接合した接合部等 に存在する種々の接合欠陥など接合界面情報が，接合部 の表面温度分布の解析により得られる事を理論的及び実 験的に明らかにした。

本報告は，前報で検出の可能性の検討を行った欠陥の うち, 内部欠陷特に未接合欠陥を対象にして，接合部の 表面温度分布の解析による欠陷寸法や位置の決定, 久陷 検出条件の選定の考方方，さらにその検出限界寸法を熱 伝導シミュレーションモデルを用いて検討したものであ る.なお，温度分布の数值解析などには前報と同様汎用 有限要素法プログラムの ANSYSを用い, コンピェータ としては, Sun SPARC station 2 を使用し, 積分夕イム ステップは約11 nsで行っている.

\section{2. 熱伝導モデルに基づく数值シミュレーシ ヨンに使用した各種材料の物性值}

熱伝導モデル構造の形状・寸法は前報で報告したもの と同様であるが，今回はリード材の熱伝導率の欠宿検出 への影響を検討するため, リード材料として Cu-Ni-Sn Alloy（C7250）のほか 42Alloy，純銅を用いた。これら の材料定数を Table 1 に示している ${ }^{1-3)}$.

\section{3. 接合部温度分布シミュレーションによる 内部欠陥の適正検出条件の選定および検 出限界寸法の検討}

\section{1 接合部表面温度分布解析による接合部欠陥寸} 法・位置の同定

まず, 内部欠陥の欠陌情報をリード表面での温度分布 の変化から抽出するために, 表面温度分布の時間的変化 および欠宿の大きさとしきい值 $\mathrm{T}_{\mathrm{c}}$ を越える温度領域の 大きさとの関係を検討した. なお，ここで，しきい值 $\mathrm{T}_{\mathrm{c}}$ とは久宿の無い接合部表面における最高温度 $\mathrm{T}_{(\mathrm{n}) \max }$ で ある. 接合界面での久陷の大きさとしては50，150，250， $350,400 \mu \mathrm{m}$ 角を想定したモデルを用いてシミュレーシ ヨンを行った. レーザ照射後 $10 \mathrm{~ms}$ および $100 \mathrm{~ms} て ゙ 250$ $\mu \mathrm{m}$ 角の欠陷が存在する接合部の表面温度でしきい值 $\mathrm{T}_{\mathrm{c}}$ を越える温度領域を調べたのが Fig. 1 (a)(b)である.図

Table 1 physical properties of the materials.

\begin{tabular}{|c|r|r|c|}
\hline $\begin{array}{c}\text { Property } \\
\text { Material }\end{array}$ & $\begin{array}{c}\text { Thermal } \\
\text { conductivity } \\
\text { W/(mK) }\end{array}$ & $\begin{array}{c}\text { Specific } \\
\text { heat } \\
\mathrm{J} /(\mathrm{Kg} \mathrm{K})\end{array}$ & $\begin{array}{c}\text { Density } \\
\mathrm{Kg} / \mathrm{m}^{3}\end{array}$ \\
\hline Pure Cu & 398.00 & 386.00 & 8880 \\
\hline $\begin{array}{c}\text { Cu-Ni-Sn } \\
\text { Alloy } \\
\text { (C7250) }\end{array}$ & 46.00 & 376.56 & 8900 \\
\hline 42 Alloy & 15.00 & 502.08 & 8250 \\
\hline Pure Sn & 64.00 & 235.00 & 7300 \\
\hline Pure In & 82.00 & 243.00 & 7310 \\
\hline Glass epoxy & 0.63 & 1500.00 & 1770 \\
\hline
\end{tabular}

からも分かるように検出時間（レーザ照射時より撮像時 までの経過時間) が $10 \mathrm{~ms}$ でも $100 \mathrm{~ms}$ でも欠陷の接合部 表面温度分布におけるしきい值 $\mathrm{T}_{\mathrm{c}}$ (時間により変化す る）を越える温度領域の大きさは $10 \mathrm{~ms} て ゙ 150 \mu \mathrm{m}, 100$ $\mathrm{ms}$ で175 $\mu \mathrm{m}$ でほ涩一定であり，またその位置も時間的 に変化していない．この事は，上記の検査対象の構造， 材料を前提にした場合，ある時間範囲内では久陷検出時

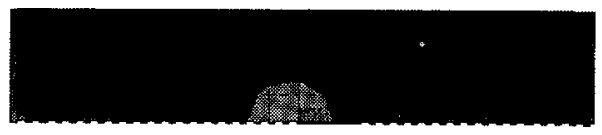

( a)

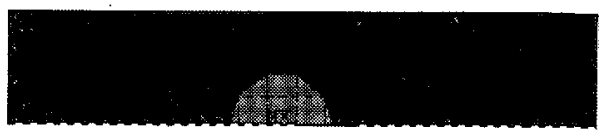

(b)

Fig. 1 Temperature distribution at the surface of the micro joint $(\mathrm{Q}: 3.2 \mathrm{~W}$, defect size $250 \times 250 \mu \mathrm{m})$. (a) laser irradiation time: $10 \mathrm{~ms}\left(\mathrm{~T}_{\mathrm{c}}: 324.3 \mathrm{~K}\right)$, (b) laser irradiation time: $100 \mathrm{~ms}\left(\mathrm{~T}_{\mathrm{c}}: 380.2 \mathrm{~K}\right)$.

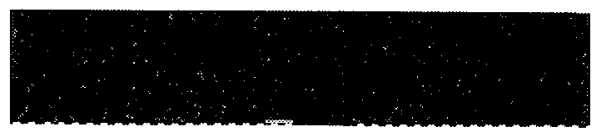

(a)

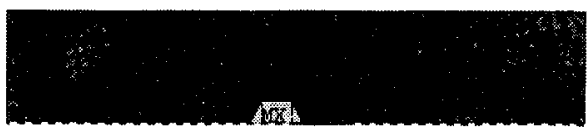

(b)

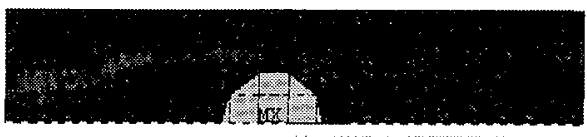

(c)

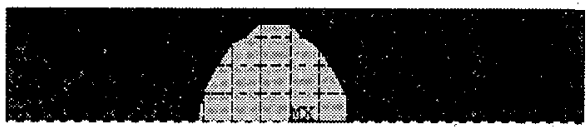

(d)

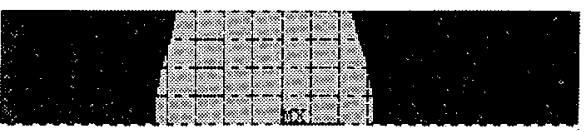

(e)

Fig. 2 Influence of defect size on temperature distribution at the surface $(\mathrm{Q}: 3.2 \mathrm{~W}$, laser irradiation time : $100 \mathrm{~ms}, \mathrm{~T}_{\mathrm{c}}: 380.2$ K). (a) defect size : $50 \times 50 \mu \mathrm{m}$, (b) defect size : $150 \times 150 \mu \mathrm{m}$, (c) defect size : $250 \times$ $250 \mu \mathrm{m}$, (d) defect size : $350 \times 350 \mu \mathrm{m}$, (e) defect size : $400 \times 400 \mu \mathrm{m}$. 


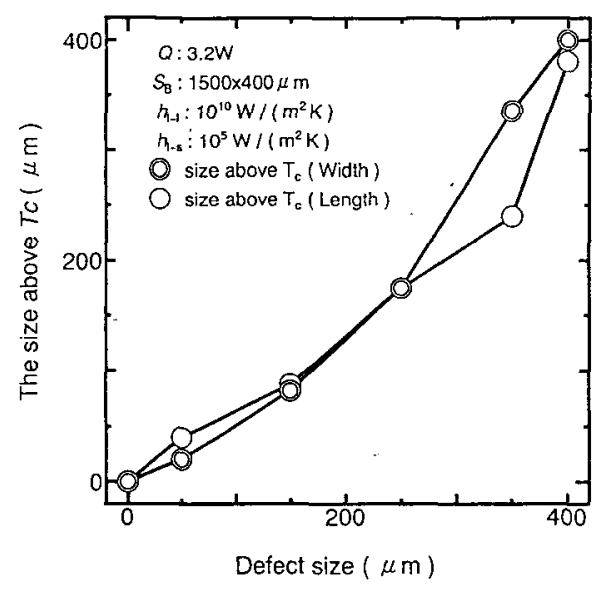

Fig. 3 Relationship between defect size and the surface temperature region above $T_{c}$ at the joints.

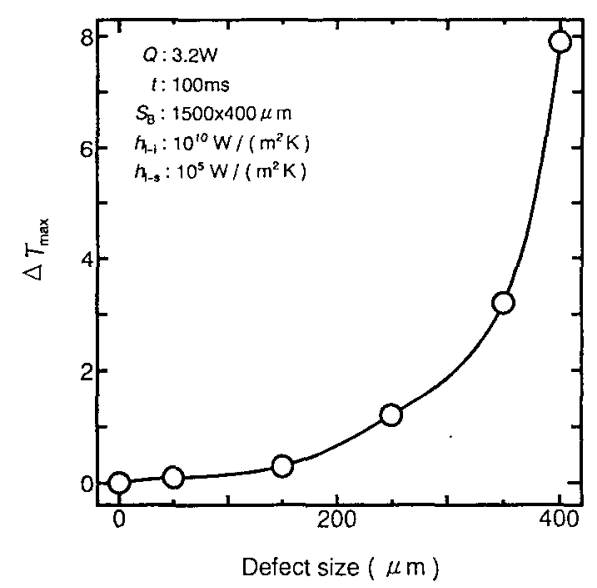

Fig. 4 Relationship between defect size and $\Delta \mathrm{T}_{\max }$.

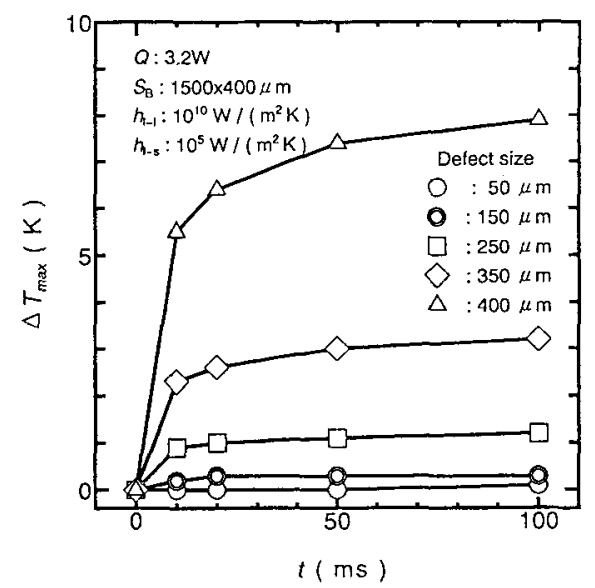

Fig. 5 Relationship between laser irradiation time and $\Delta \mathrm{T}_{\max }$ under various defect size.

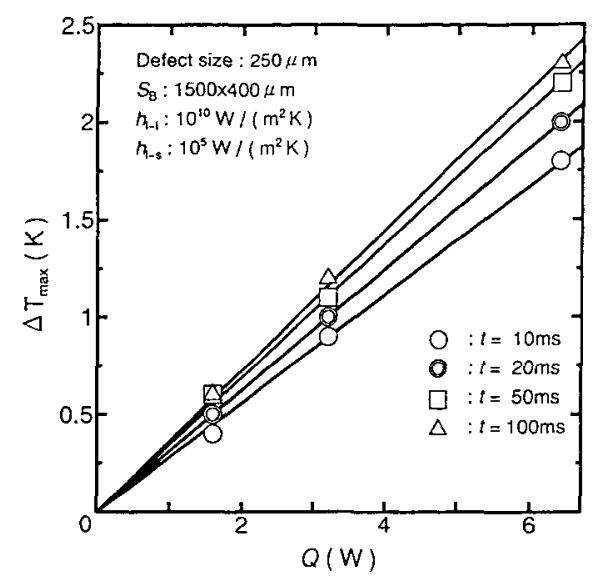

Fig. 6 Relationship between power input $Q$ and maximum surface temperature $\Delta \mathrm{T}_{\max }$ under several laser irradiation time.

間に関わらず久陷の位置が求められることを示してい る.

また欠宿の寸法を $50 \sim 400 \mu \mathrm{m}$ 角に変えたときのしき い值 $\mathrm{T}_{\mathrm{c}}$ を越える温度領域を調べたのが Fig. 2 (a)(b)(c)(d) (e)である.この図に示すとおり50 $\mu \mathrm{m}$ 角の欠楩でもその 影響は接合部表面に現れている。さらに, 欠宿の寸法が 大きくなるに従い, しきい值 $\mathrm{T}_{\mathrm{c}}$ を越える温度領域が大 きくなっており, その領域と欠陥の寸法の関係は Fig. 3 に示してある通りである。 なお，ここで，接合面積 $\mathrm{S}_{\mathrm{B}}$, 熱伝達率 $\mathrm{h}_{1-1}, \mathrm{~h}_{1-\mathrm{s}}$ は図中に示す值を採用している.この 事はしきい值 $\mathrm{T}_{\mathrm{c}}$ を越える温度領域の大きさにより50 $\mu \mathrm{m}$ 以上の久陷のサイズが決定でき, また, 欠陥寸法の増 加にともない $T_{c}$ 以上の温度領域の寸法はほ涩比例的に 大きくなる事を示している。但し，欠陥のサイズが大き くなり,リード幅に近づくに従い, $T_{c}$ 以上の温度領域の 寸法が急激に大きくなっているのは欠陥による影響がリ 一ドの端で熱が反射しているためであると思われる.

このとき, Fig. 4 に示すように $\Delta \mathrm{T}_{\max }$ は欠宿寸法が大 きくなるに従い大きくなっている.また, Fig. 5 に示すよ うに $\Delta \mathrm{T}_{\max }$ は時間的に $10 \mathrm{~ms}$ と短時間で急速に上昇し, その後上昇速度が急減する傾向にある。

な拉実際上の接合部欠楩の検出では,この $\Delta T_{\max }$ が熱 画像撮像装置の温度分解精度以上でなければ，その欠陥 が検出できないこととなり,この $\Delta \mathrm{T}_{\max }$ の大きさが久宿 の検出度合を決定する重要な因子の一つである.

\section{2 欠陷検出条件の選定についての検討}

次にレーザ照射型熱画像法による欠陥検出プロセスに おける久陷検出条件について検討する。ここに欠宿検出 条件のパラメータとしては，1）レーザ光の出力，2）レー ザ照射時閒，3)熱画取得像時間がある。このうちレーザ 照射時間と熱画像取得時間は同じ時間を採用している. ここでは, 熱画像取得時間 $(\mathrm{t})$, レーザ光の焦点での出力 （Q）について検討する事にする.

前項で欠俩検出精度を決定する因子の一つが $\Delta \mathrm{T}_{\max }$ である事を述べたが，陥寸法及び出力 Q0変化で $\Delta \mathrm{T}_{\max }$ がどの樣に変化するのか子接合界面に $250 \mu \mathrm{m}$ 角 の欠陥を作成したモデルを用いて調べたのが Fig. $6 て ゙$ ある.この図に示すように, $\Delta \mathrm{T}_{\max }$ は熱画像の取得時間 に関わらず出力 $\mathrm{Q}$ に比例する. 従って欠陥検出条件とし 
ては検出時間が短く, $\Delta \mathrm{T}_{\max }$ を大きくした方がよいが， 現実には出力 Qを大きくすると Fig.7に示すように, $\mathrm{T}_{(\mathrm{n}) \max }$ は出力 $\mathrm{Q}$ とともに大きくなり， $\mathrm{T}_{(\mathrm{n}) \max }$ が大きく なると接合部の品質を劣化させたり，検出対象部の機能 を低下させたり破壊する可能性がでてくる。また，逆に 出力 $\mathrm{Q}$ を小さくして $\mathrm{T}_{(\mathrm{n}) \max }$ を小さくし過ぎると一般に 熱画像による温度計測精度が覀くなる．そのために出力 Qの大きさはある範用に制限される。

また，熱画像取得時間 $\mathrm{t}$ に対しても熱画像撮像装置の 撮像速度 (33 ms/frame), 温度計測の精度, 熱画像の安 定性等から余り短くできない。

また，接合部の温度上昇はFig. 7 に示すように $10 \mathrm{~ms}$ までに大きく，その後ゆっくりと上昇している事より， 熱画像の取得持間の誤差を考光ると, $\mathrm{t}$ は $10 \mathrm{~ms}$ 以降の方 が良いと考えられる。

これらの事を考慮して欠陷検出条件を考えた時，赤外 線撮像装置の性能4)，対象物の酎熱性よりリード表面最 高温度 $\mathrm{T}_{(\mathrm{n}) \max }$ としては $353 \mathrm{k}\left(80^{\circ} \mathrm{C}\right.$ ) 程度を(本実験の場 合，Qにして $3.2 \mathrm{~W}$ 程度)，また熱画像取得時間 $\mathrm{t}$ として はレーザ照射開始後 $100 \mathrm{~ms}$ が適切と考えられる。

\section{3 欠陥の検出限界寸法の検討}

次に欠陷の検出限界寸法を明らかにするために前項で 選定した条件 (Q:3.2 W, t : $100 \mathrm{~ms}$ )を用いて3.2項の 条件での検出限界寸法について検討を行った。 今接合部 での熱伝導を第 1 近似として線形と考えると，欠陥のあ る接合部での温度分布は，欠楩の無い接合部の温度分布 に，你の界面よりの熱反射による温度上昇を重小合わ せたもので表現できる，そのため，久陷検出限界寸法を 決定するパラメータとして熱源の熱拡散の大小を決定す るパラメータであるリードの材質，熱源からの距離を決 めるリード厚 $\mathrm{d}_{1}$, リードから熱を奪うパラメータとして 接合界面での熱伝達係数 $\mathrm{h}_{1-1}$ がある.これらのパラメー 夕は接合部の構造が異なる事により変化する。また，こ れらのパラメータが変化すると，たとえ入熱 $(\mathrm{Q} \times \eta)$ が 一定でも $\mathrm{T}_{(\mathrm{n}) \max }$ が変化する.そこで,ここでは $\mathrm{T}_{(\mathrm{n}) \max }$ が 一定となる条件下でリード材質, リード厚 $d_{1}$, 熱伝達係 数 $\mathrm{h}_{1-1}$ の影響を検討した。

まず，リードの材質による欠陷検出限界寸法への影響 を調べるためにリード材質の $\Delta T_{\max }$ への影響を検討し た.ここで,リードの材質としては, 42Alloy, 純銅, $\mathrm{Cu}$

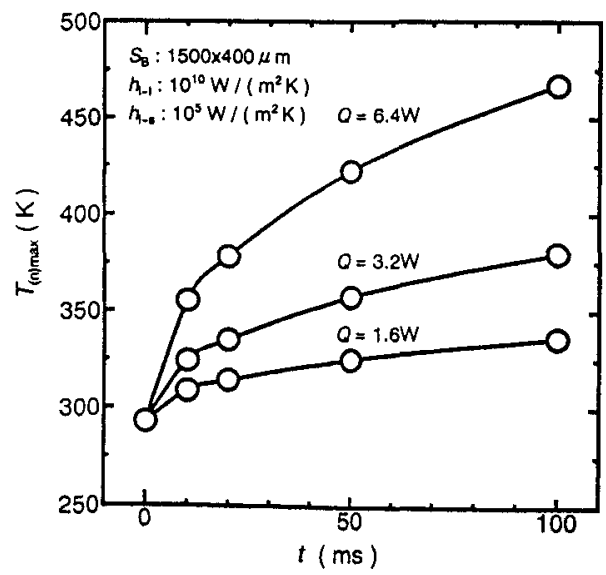

Fig. 7 Relationship between $\Delta T_{\max }$ and time under several laser power input.
一Ni-Sn Alloy を用いた. なお，これらの材質を採用した のは契用上リード材として採用され，かつその温度拡散 係数が、それぞれ $3.62 \times 10^{-6}, 1.17 \times 10^{-4}, 1.37 \times 10^{-5} \mathrm{~m}^{2} /$ sと大きく異なっているためである.

これらのリードを用いたシミュレーション結果に Fig. 8 に示す。この図に示すように $\Delta \mathrm{T}_{\max }$ は 42Alloy， $\mathrm{Cu}-\mathrm{Ni}-\mathrm{Sn}$ Alloy, 純銅と温度拡散係数が大きくなるほ ぞ小さくなる，つまり，温度拡散係数が小さいほど欠陥 による温度分布の変化を拡散させにくいため $\Delta \mathrm{T}_{\max }$ が 大きくなり，准の検出限界寸法がより小さくなる事を 示している.

次に,リード厚 $\mathrm{d}_{1}$ の欠楩検出限界寸法への影響を調心゙ るためにリード厚 $\mathrm{d}_{1}$ の $\Delta \mathrm{T}_{\text {max }}$ への影響を検討した。な おりード厚として $50,100,150 \mu \mathrm{m}$ (いずれも Snメッキ $22 \mu \mathrm{m}$ を付加している) を用いた，これらのリード厚 $\mathrm{d}_{1}$ を用いたシミュレーション結果を Fig. 9 に示す.この図 に示すようにリード厚的が薄くなればなるほど $\Delta T_{\max }$ が大きくなっていく事が理解される。これは陥から観 察面の距離が小さくなるにつれて欠宿の影響が出易く，

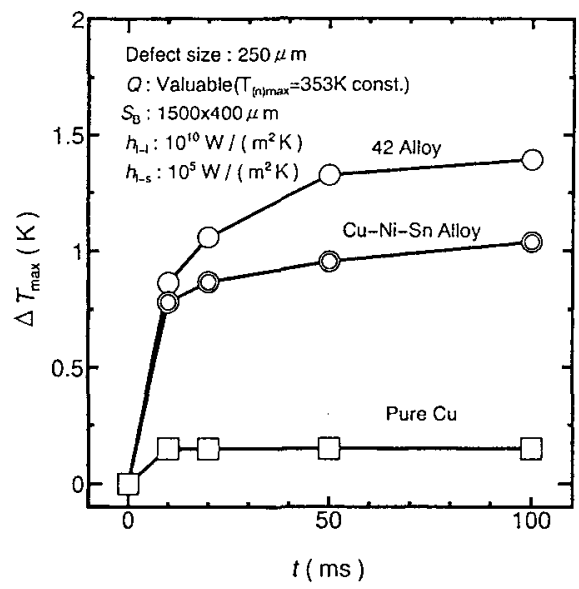

Fig. 8 Behavior of $\Delta T_{\max }$ under several lead materials with different heat difusivity (Defect size : $250 \mu \mathrm{m}, \mathrm{t}: 100 \mathrm{~ms}$ ).

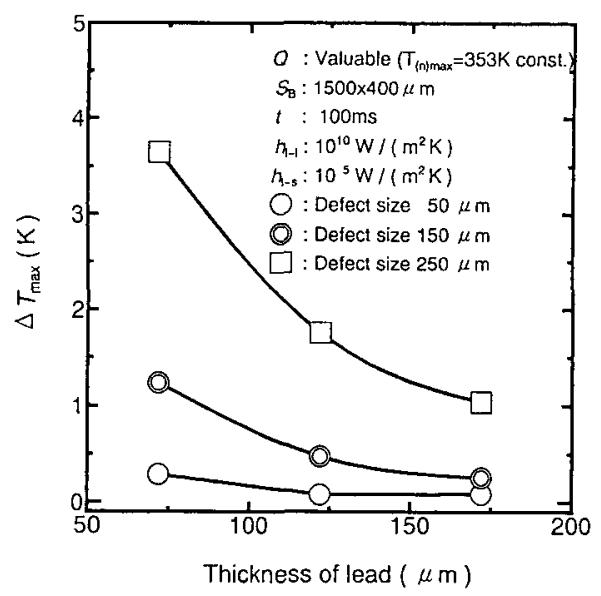

Fig. 9 Relation between $\Delta \mathrm{T}_{\max }$ and lead thickness under several defect size (Defect size : $250 \mu \mathrm{m}, \mathrm{t}: 100 \mathrm{~ms})$. 


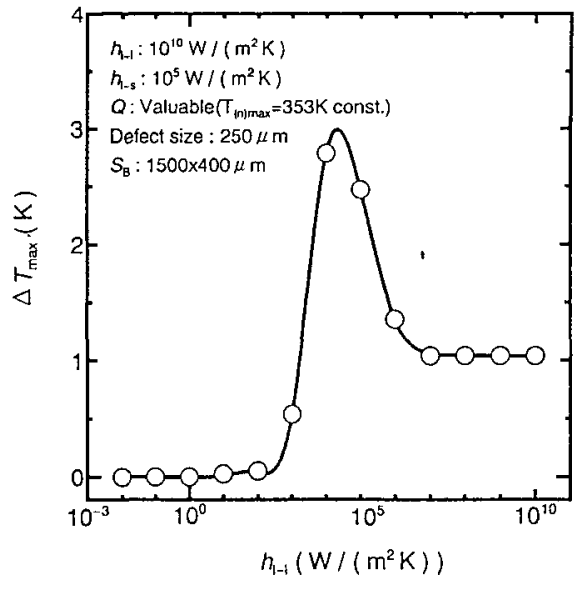

Fig. 10 Influence of $h_{1-1}$ on $\Delta T_{\max }$ (Defect size : $250 \mu \mathrm{m}, \mathrm{t}: 100 \mathrm{~ms}$ ).

欠陌の検出限界寸法がより小さくなる事を示している.

次に，接合部界面の熱伝達係数 $\mathrm{h}_{1-1}$ の久陷㭘出限界寸 法への影響を調べるために接合部界面の熱伝達係数 $h_{1-1}$ の $\Delta T_{\max }$ への影響を検討した。な扔, 接合部界面の熱伝 達係数 $\mathrm{h}_{1-1}$ としては $10^{-2} \mathrm{~W} /\left(\mathrm{m}^{2} \mathrm{~K}\right)$ から $10^{10} \mathrm{~W} /\left(\mathrm{m}^{2} \mathrm{~K}\right)$ までを用いた。これらのモデルのシミュレーション結果 をFig. 10 に示す。図に示すように接合部界面の熱伝達 係数 $\mathrm{h}_{1-1}$ が小さくなるにつれて $\Delta \mathrm{T}_{\max }$ は初め一定であ るが, $\mathrm{h}_{1-1}$ が107 $\mathrm{W} /\left(\mathrm{m}^{2} \mathrm{~K}\right)$ 以下になると, $\Delta \mathrm{T}_{\max }$ が大き くなっていき $\mathrm{h}_{1-1}$ が $10^{4} \mathrm{~W} /\left(\mathrm{m}^{2} \mathrm{~K}\right)$ 付近で $\Delta \mathrm{T}_{\text {max }}$ が最大 となり, それを越えると, 再び小さくなり, $\mathrm{h}_{1-1}$ が $10^{2} \mathrm{~W} /$ $\left(\mathrm{m}^{2} \mathrm{~K}\right)$ になると, $\Delta \mathrm{T}_{\max }$ がほほ止0になる。これは, 熱伝 達係数が大きいときは,ランドに熱を奪われすぎるため， 欠陷による温度分布の変化が拡散され，また $h_{1-1}$ が小さ いと, $h_{d}$ との差がなくなり, 欠楩による温度変化は小さ くなってしまうからであると考えるられる。

\section{4. 結論}

ガラスエポキシ基板上の銅ランドに銅合金リード，純 銅リード及び42Alloyリードを接合したマイクロ接合 部にレーザを短時間照射した場合の接合部内部温度分布 および表面温度分布を熱伝導モデルを用いて数值解析 し，レーザ照射型熱画像法による各種欠宿の適正検出条 件の考え方および検出可能な欠陥寸法とリード材，リー ド寸法, 接合界面での熱伝達係数との関係について理論 的に検討した。この主な結果は以下の通りである。
1）末接合またはボイドのような内部欠陷寸法，位直 はリードおよび基板などの材質, 形状寸法が与えられた 場合, 欠陷が存在する場合のリード表面での温度分布よ り欠陥がない場合の最高温度で 2 値化された温度領域の 寸法, 位置で検出しうる。

また，内部欠宿が存在することによる表面温度上昇 $\Delta \mathrm{T}_{\max }$ は欠陥寸法が大きくなるとともに上昇する傾向 にある。

2) 久陷検出の為の適正条件は，接合部の温度上昇速 度, $\Delta \mathrm{T}_{\max }$ と時間や入熱との関係, 赤外線検出素子の特 性と接合部の耐熱性を勘案した上で $\Delta T_{\text {max }}$ を最大にす る条件にすることが必要である，本実験ではリード表面 最高温度としては $353 \mathrm{~K}\left(80^{\circ} \mathrm{C}\right)$ 程度を, また熱画像の撮 像時間としてはレーザ照射開始後 $100 \mathrm{~ms}$ が適切な条件 となる。

3）未接合またはボイドの久陷検出限界寸法は，リー ド材が Cu-Ni-Sn Alloy の場合, リード厚150 $\mu \mathrm{m}$ で約 $50 \mu \mathrm{m}$ の接合欠楩が検出可能となる。また，欠陷検出限 界寸法はリードの材質にも依存し，同じ250 $\mu \mathrm{m}$ の欠陷 でも温度拡散係数が大きな純銅のリードの場合 $\Delta T_{\max }$ は Cu-Ni-Sn Alloy の場合の約0.08倍となり, 逆に温度 拡散係数が小さい 42Alloyりードの場合 $\Delta \mathrm{T}_{\max }$ は約 1.7 倍となり，温度应散係数が小さくなるにつれて娭出精度 が向上する。

4）未接合またはボイドの欠陷検出精度はリードの厚 さに依存し，同じ $250 \mu \mathrm{m}$ の欠陥でも $50 \mu \mathrm{m}$ 厚の場合だ と,150 $\mu \mathrm{m}$ の場合の $\Delta \mathrm{T}_{\max }$ の值の約3.4倍の值となり, 欠楩検出精度が向上する。

5）検出可能な未接合またはボイドの欠宿検出精度は $\mathrm{h}_{1-1}$ に依存し, $\mathrm{h}_{1-1}$ が $10^{4} \mathrm{~W} /\left(\mathrm{m}^{2} \mathrm{~K}\right)$ 付近で $\Delta \mathrm{T}_{\text {max }}$ が最大 となる、また, $\mathrm{h}_{1-1}$ がそれ以上になると, 小さくなり, $10^{7}$ $\mathrm{W} /\left(\mathrm{m}^{2} \mathrm{~K}\right)$ になると, $\Delta \mathrm{T}_{\max }$ が一定になる。また, $\mathrm{h}_{1-1}$ が それ以下になっても小さくなり，10 $10^{2} \mathrm{~W} /\left(\mathrm{m}^{2} \mathrm{~K}\right)$ になると $\Delta \mathrm{T}_{\max }$ がほ涩0になる。

\section{参 考 文 献}

1）日本機械学会編，“伝澾工学資料改訂第 4 版”, 日本機械学会, (1987), p. 314-316.

2）三菱電機㑣，合金製品技術資料，No. 277006 .

3）日本マイクロエレクトロニクス協会編, “厚膜 IC 化技術”, 工業 調査会, (1984), p. 8.

4）仲田ら：「マイクロ接合部に抢ける久陥検出の可能性ーレーザ 照射型熱画像法によるマイク口接合部の欠陥検出法に関する研 究 (第 1 報) 一」, 溶接学会論文集, Vol. 11(1993), No. 4, p. 509 -515 . 